\title{
Different strains of rats develop different clinical forms of adjuvant disease
}

\author{
VALERIE Y. MUIR AND D. C. DUMONDE \\ From the Department of Immunology, St Thomas's Hospital Medical School, London SE1 7EH
}

SUMMARY Evidence is presented that a single injection of bacterial antigen in oil into a footpad of rats of 5 strains induced different clinical forms of adjuvant disease in the individual rat strains. Rats were injected with $300 \mu \mathrm{g}$ heat-killed Mycobacterium tuberculosis in $50 \mu \mathrm{l}$ paraffin. Inflammatory lesions and clinical features were recorded on skeletal charts at frequent intervals after injection; methods of charting and quantifying the features are described. By individually marking the rats and using one or more charts per rat we obtained an objective record of the course of disease in each animal and thus a means of distinguishing clinical features from manifestations of disease severity. Evaluation of these records showed that there was a pattern of joint involvement and associated physical and clinical features specific to each strain and that such strain specificity was reproducible in groups of rats injected over periods up to $3 \frac{1}{2}$ years. These results suggest that the clinical form of adjuvant disease developing in each rat in response to the injection of mycobacteria in oil is genetically determined, and that there are additional factors that interact with genetic ones to allow adjuvant disease to develop in a particular rat.

Adjuvant disease is an experimental disorder of rats induced by a single injection of killed mycobacteria or other organisms in oil. Inflammatory lesions of ears and uninjected paw joints develop after a latent interval of about 10 days $^{1-4}$ and increase in number and intensity of inflammation until about the third week, after which they regress. The rats do not recover completely, as they develop residual joint deformities and recurrent inflammation of paw joints. Sometimes large joints and the spine may be inflamed, and there may also be lymphoid enlargement, anterior uveitis, ${ }^{5}$ vasculitis, urethritis, and pannus formation in the joints. ${ }^{67}$ On the basis of such clinical manifestations it was suggested that adjuvant disease might represent a model of some inflammatory rheumatic disorders of man, most notably rheumatoid arthritis, ankylosing spondylitis, and Reiter's disease. There is a stong association of these human disorders with antigens of the major histocompatibility complex, ${ }^{8}$ and several studies have shown that susceptibility to adjuvant disease differs in different inbred strains of rats. Differences in clinical form of the disease are acknowledged but described briefly and subjectively, and are not dis-

Accepted for publication 23 July 1981 .

Correspondence to Dr V. Y. Muir, Department of Immunology, King's College Hospital, Denmark Hill, London SE5 8RX. tinguished from disease severity, so that it is difficult to assess the significance of such observations. ${ }^{19-11}$

During initial studies with the SK Wistar rat we noticed that some reproducible features of adjuvant disease differed from those described previously. Accordingly we set out to compare features of the disease in SK rats with those developing in 4 other strains by recording them objectively on skeletal charts. In this paper we describe the method of recording, demonstrate how the data obtained are analysed to identify and quantify clinical features of adjuvant disease, show how clinical features may be distinguished from manifestations of disease severity, and how the data provide evidence that each strain of rat develops a different clinical form of adjuvant disease. We suggest that the particular form of inflammatory rheumatic disease developing in each rat as a consequence of the injection of mycobacteria in oil is genetically determined and that histocompatibility antigens of the rat interact with certain antigens of mycobacteria in some way to induce such disease.

\section{Materials and methods}

Rats and immunisation. Rats were of 5 strains: highly inbred SK Wistar and Spontaneously Hypertensive, 
SH (Okamoto) rats from the hospital animal colony; AHR and AHN rats supplied by Allen and Hanbury's Research Ltd, derived from SpragueDawley X Wistar and inbred for 20 generations (F 16-20 used for this study); closed colony Wistar rats purchased from A. Tuck and Sons, Essex. All rats were individually marked and aged 3 to 5 months when injected; some $\mathrm{SH}$ rats were aged 8 months. Each rat was given a single injection of pulverised, heat-killed Myco. tuberculosis $(300 \mu \mathrm{g})$ in paraffin $(50 \mu \mathrm{l})$ intradermally in the left hind footpad under ether anaesthesia. Rats were housed in heatcontrolled rooms with 16 hours of light daily; all injections were given between 9.30 and $11.30 \mathrm{am} ; 2$ batches of Myco. tuberculosis (strains C, DT, and PN mixed) were used during this study. Controls were injected with paraffin only.

Recording inflammatory lesions and clinical features. A skeletal chart was used for recording and quantifying (scoring) inflammatory lesions as shown in Fig. 1. Rats were examined up to 6 times weekly, when inflammation of individual joints of the 3 uninjected paws, ears, and tail were recorded on a chart. Inflammation was identified by erythema only, and it was recorded only as present, that is, without assessment of severity. Additional clinical features of interest such as rashes and ulcers were also noted; these were also photographed to provide an objective record of their characteristics. Inflammation of large joints was identified by limitation of passive movement and of the spine by resistance to passive extension. Post-mortem examination was done on selected rats. Thus by using one or more charts per rat an objective record was obtained of the course of disease in each animal. The joint score was calculated for each day of examination; the maximum for any day was 67.

Criteria for adjuvant disease. One or more inflammatory lesions remote from the injection site and lasting at least 48 hours constituted adjuvant disease.

Experimental design. Experimental groups comprised at least 8 rats. Initially features of adjuvant disease in SK Wistars were identified by comparing experimental rats with controls of the same strain, injected on the same day. Subsequently rats of other strains were observed in parallel with SK Wistars and with controls. In this way differences in clinical features (such as rashes or ulcers) could be evaluated and recorded when relevant. By photographing clinical features the reproducibility of the characteristics could be ascertained in subsequent groups of each strain.

\section{Results}

This study extended over $3 \frac{1}{2}$ years; approximately 25
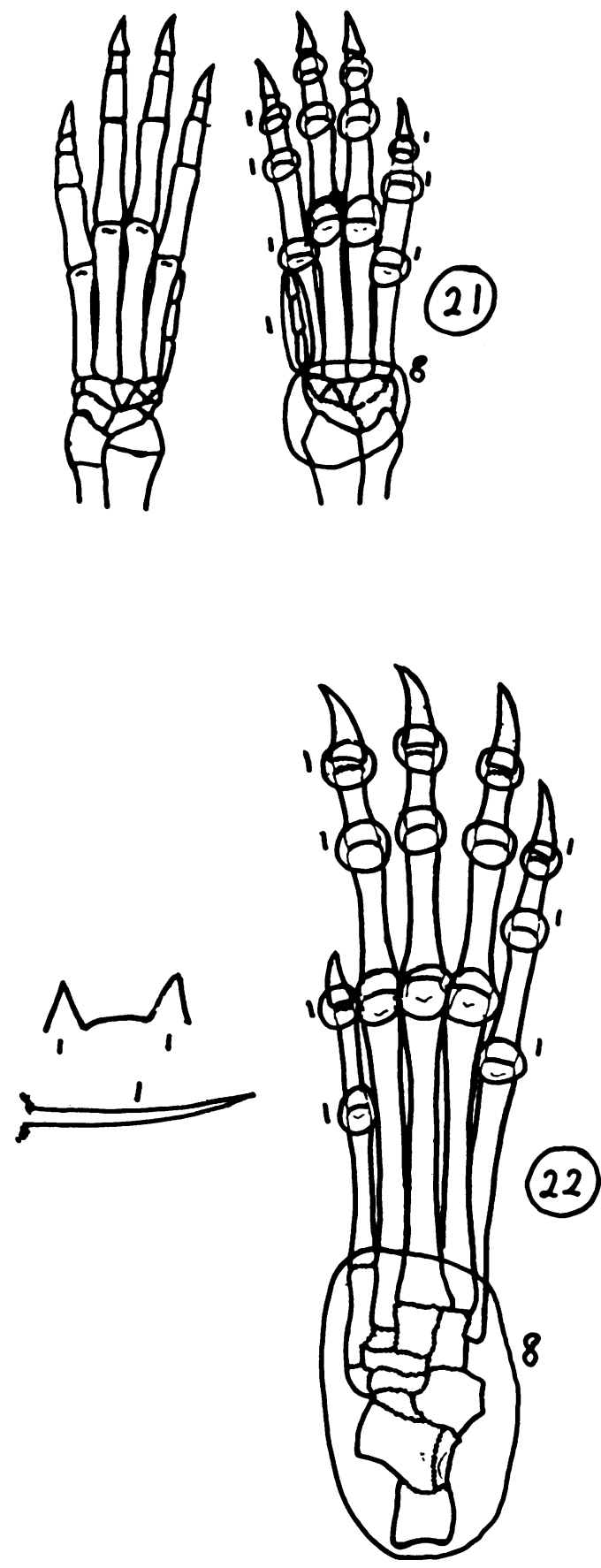

Fig. 1 Skeletal chart used for recording and scoring the inflammatory lesions of adjuvant disease. Maximum score for any day is 67 (forefeet 21 each; $R$ hindfoot 22; ears 1 each; tail 1). 
groups of SK Wistars were studied during this time. Four groups of AHN, 3 of AHR, and 8 of SH rats were injected over 18-month periods; 2 groups of Tuck rats were observed over 2 to 3 months. Within each group of each strain the number of inflammatory lesions, their duration, and degree of swelling varied with the individual rats; these are manifestations of disease severity. The severity also varied between the different groups, and we have discussed this in detail elsewhere. ${ }^{12}$ The occurrence of clinical features also varied within a group: the first day on which inflammatory lesions were manifest varied between different rats, as did the rate at which new lesions appeared; not all rats of a group developed rashes or ulcers. Between groups of one strain, however, the first day on which inflammatory lesions appeared in any rat, the mean rate of dissemination of inflammatory lesions, and the incidence and characteristics of clinical features were reproducible; some features occurred only in one strain.

Table 1 lists reproducible physical and clinical features of adjuvant disease in each strain of rat. It is seen that not all rats of the AHN and SH strains developed adjuvant disease and that the minimum latent interval varied with the strain. The ear lesions characteristic of adjuvant disease (erythematous nodule, papule, or blister-like lesion) did not occur regularly in rats of the AHN and SH strains; instead the AHN rats developed erythematous papules only, and in a few SH rats small nodules developed. In Tuck, AHR, and SH rats joint involvement showed a characteristic and specific pattern. In Tuck rats all joints were inflamed, but spinal involvement was prominent, and a kyphoscoliosis had developed by day 14. By contrast in AHR rats the spine and hips remained mobile despite intense inflammation of other limb joints. In SH rats wrist inflammation was prominent and was frequently the only site of inflammation. Many of the SH rats developed large granulomas of the wrists and injected foot that increased in size continuously until they were killed.

Of particular interest was the minimum latent interval which differed widely between the strains and was independent of the time to reach maximum joint score. Thus in AHR rats the minimum latent interval was only 6 days, while the time to reach maximum joint score in this strain exceeded that of the SK, Tuck, and AHN strains. Tuck rats developed gross lymphoid enlargement early, but in AHR rats splenic enlargment and minimal lymph node hypertrophy occurred late. The most characteristic strain-specific feature was the vasculitis of the tail developing in $15 \%$ of SK rats (Fig. 2). This was manifest as a purpuric rash between days 28 and 34 on the distal third of the tail, which may subsequently become gangrenous. We have never seen vasculitis of the tail in any rat of another strain despite regular observation up to day 42 , with many longer periods of observation up to 1 year.

The rate at which inflammatory lesions appeared in each strain of rat is represented by the mean joint score at intervals after injection (Fig. 3). SK and Tuck

Table 1 Features of adjuvant disease in 5 strains of rats

\begin{tabular}{|c|c|c|c|c|c|}
\hline & \multicolumn{5}{|l|}{ Strain of rat } \\
\hline & $S K$ & Tuck & $A H R$ & $A H N$ & $S H$ \\
\hline No. rats injected & 300 & 13 & 17 & 19 & 54 \\
\hline \% Rats with disease & 99 & 100 & 100 & 89 & 32 \\
\hline $\begin{array}{l}\text { Minimum latent interval } \\
\text { (days)* }\end{array}$ & 9 & 9 & 6 & 8 & 17 \\
\hline $\begin{array}{l}\text { Ear lesions. Incidence } \\
(\%) \text { in diseased rats }\end{array}$ & 100 & 100 & 100 & $\begin{array}{l}\text { Atypical lesions } \\
\text { (red papules only) in } \\
\text { all rats }\end{array}$ & 4 \\
\hline Joints inflamed & $\begin{array}{l}\text { Paws, knees elbows } \\
\text { usually. Hips and } \\
\text { spine in severely } \\
\text { affected rats }\end{array}$ & $\begin{array}{l}\text { All joints severely. } \\
\text { Spinal inflammation } \\
\text { early and very } \\
\text { prominent }\end{array}$ & $\begin{array}{l}\text { Paws, knees, elbows } \\
\text { only }\end{array}$ & $\begin{array}{l}\text { Paws, wrist, ankle. } \\
\text { Large joints and spine } \\
\text { in severely affected } \\
\text { rats }\end{array}$ & $\begin{array}{l}\text { Wrists only in most } \\
\text { rats }\end{array}$ \\
\hline $\begin{array}{l}\text { Time to reach maximum } \\
\text { joint score (days) }\end{array}$ & 21 & 14 & 30 & 25 & 21 \\
\hline $\begin{array}{l}\text { Lymphoid enlargement }{ }^{\dagger} \\
\text { before day } 21\end{array}$ & Moderate & $\begin{array}{l}\text { Gross, with huge } \\
\text { fibrous nodes }\end{array}$ & After day 40 only. & Moderate & Not known \\
\hline Vasculitis & $\begin{array}{l}\text { Purpura }+ \text { gangrene } \\
\text { of tail from day } 28 \text { in } \\
15 \%\end{array}$ & No & $\begin{array}{l}\text { Gangrene of digits from } \\
\text { day } 26 \text { in } 12 \%\end{array}$ & No & No \\
\hline Skin ulcers & $\begin{array}{l}\text { Superficial, transient, } \\
\text { lasting } 24 \text { hours }\end{array}$ & $\begin{array}{l}\text { Deeper lasting several } \\
\text { days }\end{array}$ & $\begin{array}{l}\text { Small, deep, 'punched } \\
\text { out' }\end{array}$ & $\begin{array}{l}\text { Superficial, lasting } 24 \\
\text { hours }\end{array}$ & None \\
\hline $\begin{array}{l}\text { Recovery from initial } \\
\text { phase of inflammation } \\
\% \text { of diseased rats }\end{array}$ & 100 & 23 & 24 & 0 & 57 \\
\hline
\end{tabular}

${ }^{*}$ Defined as the first day on which any rat of the group developed inflammatory lesions.

tIdentified from post-mortem examination. 


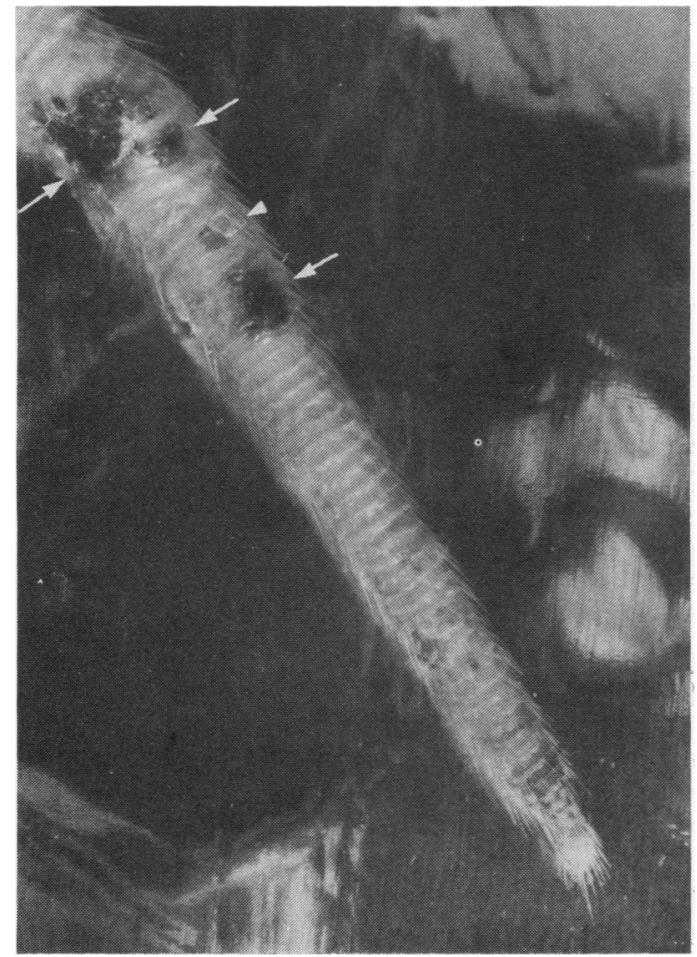

Fig. 2 Vasculitis of tail in SK Wistar on day 29. Three uicerated and necrotic lesions are arrowed; the narrowed tip is gangrenous. Triangle indicates a purpuric spot that has not yet ulcerated.

rats developed maximum joint score during a few days, whereas in AHR rats this did not occur until 2 or 3 weeks after the first inflammatory lesion appeared. In SK rats the joint score returned to 0 at about day 50 (not shown), and, after this, recurrent inflammation of 2 or 3 paw joints and the tail occurred, characteristically lasting for up to 5 days at a time. Only in the SK strain did all rats start to recover shortly after day 21 . No recovery of Tuck rats was apparent by day 28; surviving AHN rats developed chronic unremitting joint inflammation, and in SH rats few joints were inflamed but the lesion did not resolve.

Three criteria were used to evaluate and compare features of disease onset in individual rats of the different strains up to day 21 (Fig. 4). These were (a) day of onset of inflammatory lesions; $(b)$ maximum joint score attained by day 21 ; (c) time of maximum joint score. All SK rats developed maximum joint score by day 21 , and thus these were taken as 'standard' and other strains were compared with them, by $\chi^{2}$ test (Figs. 4a and c) and Mann-Whitney U test (Fig. 4b). Tuck rats developed lesions significantly earlier than SK rats (Fig. $4 a ; p<0.001$ ) and AHN and AHR rats significantly later $(p<0.05)$; Tuck rats attained a significantly higher joint score by day 21 (Fig. 4b; $\mathrm{p}<0.001$ ) and AHN rats a significantly lower score $(p<0.05)$, while rats of the AHR strain did not differ from SK rats in respect of the score attained $(p>0 \cdot 1)$. The time taken to attain maximum joint score was significantly shorter in Tuck rats (Fig. $4 c ; p<0.001$ ), but significantly longer in AHN and AHR rats $(p<0 \cdot 05)$. Few SH rats (data not shown) developed joint lesions before day 21 , and in none did the joint score exceed 24 . Therefore it may be concluded that each of the 5 strains showed a distinctive pattern of development of inflammatory lesions or mode of onset of adjuvant disease. These findings are summarised in Table 2.

No differences were detected between groups of the SK, AHN, and AHR rats that could be ascribed to differences between the two batches of Mycobacterium tuberculosis.

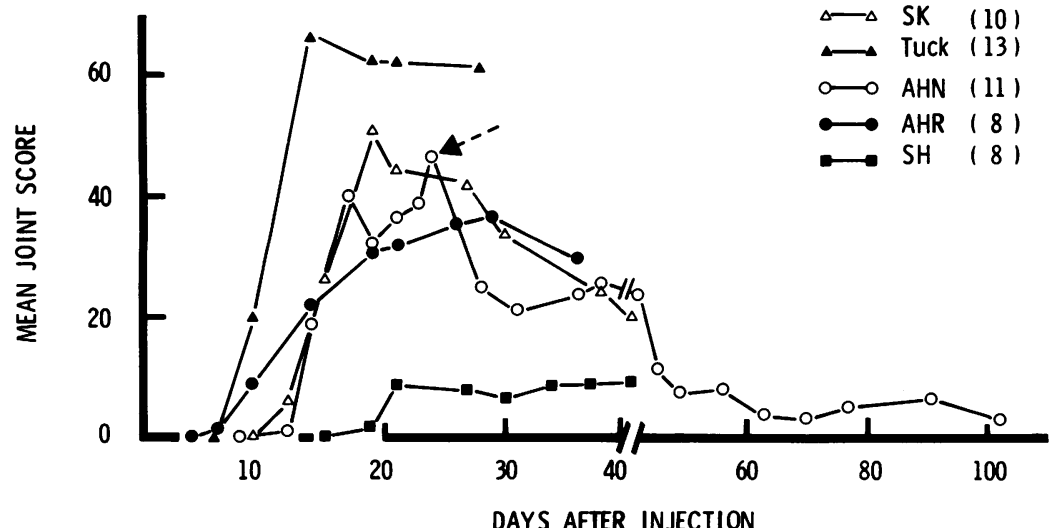

DAYS AFTER INJECTION
Fig. 3 Peripheral joint inflammation (joint score) at intervals after injection in rats of 5 strains. Representative groups to illustrate strain-specific characteristics; number in each is given in parentheses. With Tuck and $A H R$ rats experiments were terminated when most rats were unable to feed or groom because of severe and unremitting joint inflammation (10/13 Tuck; 6/8 AHR); arrow indicates when 5 AHN rats were killed for the same reason. 


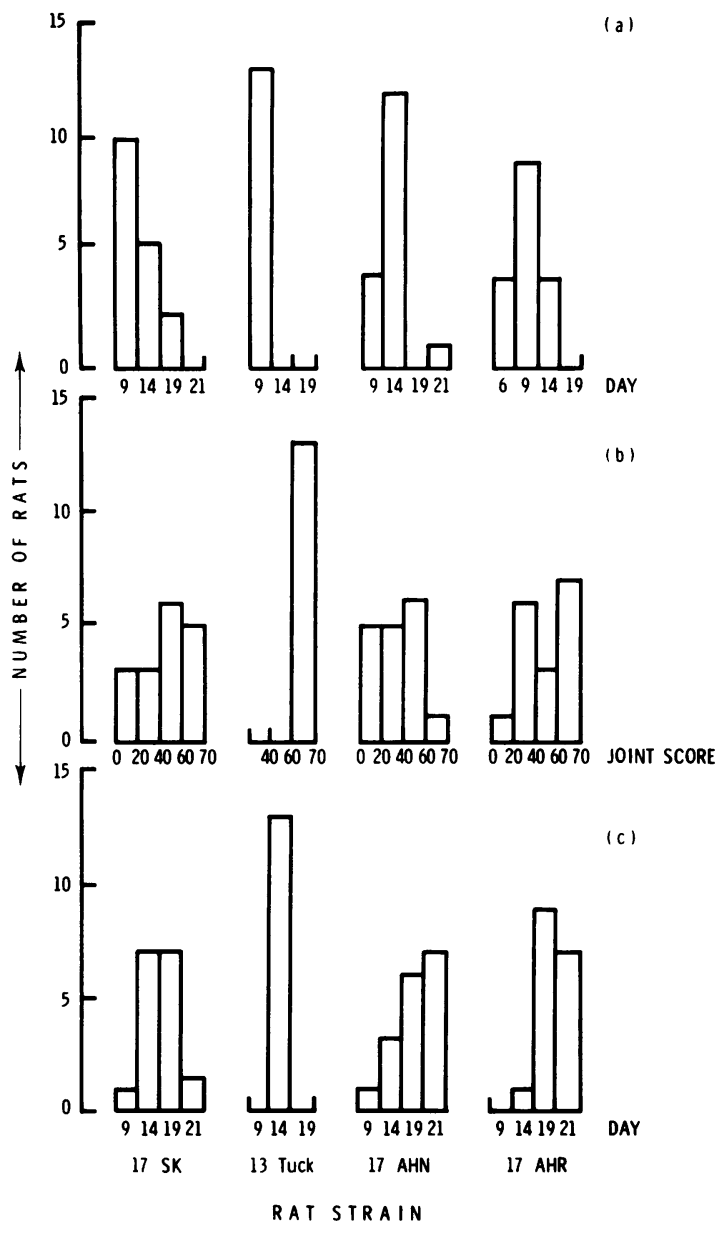

Fig. 4 Mode ofonset of adjuvant disease in 4 strains of rats: (a) first day on which inflammatory lesions were recorded in each rat; (b) maximum score attained in each rat by day 21; (c) the day on which each rat attained maximum score.

Table 2 Onset of adjuvant disease: features in Tuck, $A H N$, $A H R$, and SH strains as compared with $S K$ rats

\begin{tabular}{llll}
\hline Rat strain & $\begin{array}{l}\text { (a) } \\
\text { First day when } \\
\text { lesions recorded }\end{array}$ & $\begin{array}{l}\text { (b) } \\
\text { Maximum joint } \\
\text { score attained }\end{array}$ & $\begin{array}{l}\text { (c) } \\
\text { Time when max. } \\
\text { score attained }\end{array}$ \\
\hline Tuck & Earlier & Higher & Sooner \\
AHN & Later & Lower & Later \\
AHR & Later & Same & Later \\
SH & Later & Lower & Later \\
\hline
\end{tabular}

a, b, and c related to Fig. 4 .

\section{Discussion}

In this paper we have described a new method of recording features of adjuvant disease. It is objective in that lesions are recorded only as present, that is, without assessment of severity. Clinical features were also recorded, but an objective record was obtained by photography. Rats were individually marked, and so the charts formed records of the number, site, and nature of lesions on each day of examination throughout the period of observation. We devised a method of scoring inflammatory lesions, and thus manifestations of the disease could be compared within and between the strains.

The variable and unpredictable course and severity of adjuvant disease in individual rats and between groups was confirmed by these data and is described and discussed separately. ${ }^{12}$ However, the charts provided a means of comparing the general and mean characteristics of groups within and between the different strains and when the data was analysed in this way, evidence of reproducible characteristics was obtained. Some gross features occurred only in one strain-for example, the long latent interval and predominance of wrist inflammation in SH rats. Only reproducible features are described in this paper. When the characteristics were tabulated by strain as in Table 1 it was apparent that there were differences in the clinical form of adjuvant disease and that there was a reproducible combination of physical, qualitative, and quantitative features specific to each strain. There were also characteristic modes of progression and regression of joint inflammation and chronicity (Fig. 3) and each strain was significantly different from all other strains in the mode of onset of the disease (Fig. 4 and Table 2). Therefore we suggest that we have demonstrated that the disease developing in response to the single injection of mycobacteria in oil is of a different clinical form in each strain of rat. In all the strains the chief manifestation was joint inflammation, but the precise joints affected by the inflammatory process and the associated clinical features varied with, but were specific to each strain. Thus a spectrum of inflammatory rheumatic disease seemed to occur across these 5 strains.

Questions arise, first, as to why this has not been described previously; secondly, as to the possible implications of these findings and whether they suggest aetiological or pathogenetic mechanisms of rheumatic disease in man. Different clinical forms of adjuvant disease have been described subjectively by Glenn et al., ${ }^{10}$ Swingle et al., ${ }^{9}$ and Perlik et al., ${ }^{11}$ but none of these authors followed up the observation. Other methods of recording features of adjuvant disease have been described, ${ }^{413}{ }^{14}$ but these were concerned primarily with disease severity and are subjective at least in part. Thus no objective method of recording features of the disease has been described previously, and without such methodology this 
detailed comparison of clinical features would not have been possible.

In rats only killed mycobacteria induce joint inflammation; live organisms cause a mycobacterial infection ${ }^{15}{ }^{16}$ but not joint disease (N. C. Oswald, personal communication). Despite the use of highly inbred rats, the disease is of variable severity within a group, ${ }^{1}$ and some rats of a group may not develop disease. Uniformity of the immune response would be expected in such rats, but it is recognised that other characteristics which may affect or be independent of the immune response, ${ }^{17}{ }^{18}$ may vary within a strain. The SK, SH, and Tuck rats are Wistar substrains; AHR and AHN rats are derived from Sprague-Dawley $\mathrm{X}$ Wistar rats. Therefore it is probable that all 5 strains have common or related MHC antigens. All the strains had joint inflammation, but the particular joints inflamed and the associated clinical features varied. It is suggested that MHC antigens may define the joint involvement and interaction with minor histocompatibility antigens (characteristic to each substrain), the associated clinical features.

The varying susceptibility might be explained similarly, but the absence of disease in some rats of the AHN and SH strains suggests more that the immune response to the injected organism may be modified in such animals. Adjuvant disease may be induced by selected strains of a wide variety of common environmental organisms, so that rats could well be exposed (and sensitised) to such organisms early in life. It is not known if such pre-exposure is necessary for the development of adjuvant disease, but it is suggested that major and minor histocompatibility antigens interact in some way with environmental organisms to manifest a particular clinical form of inflammatory rheumatic disease after injection of (or specific mode of exposure to), an appropriate organism.

We thank Mr D. Page and Mrs J. Ludlow for technical assistance; Mr G. Thompson and Mr I. Brown and staff for helpful cooperation; Miss S. Chinn for statistical advice; and Dr A. MacKenzie, Allen and Hanbury's Ltd, for supplying rats. Financial support was provided by Warner Lambert-Parke Davis and the Arthritis and Rheumatism Council.

\section{References}

${ }^{1}$ Pearson C M, Chang Y H. Adjuvant disease; pathology and immune reactivity. Ann Rheum Dis 1979; 38 (suppl): 102-10.

${ }^{2}$ Paronetto F. Adjuvant arthritis induced by Corynebacterium rubrum. Proc Soc Exp Biol Med 1970; 133: 296-8.

${ }^{3}$ Kohashi O, Pearson C M, Beck F W, Narita T, Kotani S. Arthritogenicity in rats of cell walls from several streptococci, staphylococci and two other bacteria. Proc Soc Exp Biol Med 1976; 152: 199-203.

4 Pearson C M. Development of arthritis in the rat following injection with adjuvant. In: Shaffer J H, LoGrippo G A, Chase M W, eds. Mechanisms of Hypersensitivity. London: Churchill, 1959: 647-71.

${ }^{5}$ Waksman B H, Bullington S J. Studies of arthritis and other lesions induced in rats by the injection of mycobacterial adjuvant. III. Lesions of the eye. Arch Ophthalmol 1960; 64: 751-62.

${ }^{6}$ Pearson C M, Wood F D. Studies of arthritis and other lesions induced in rats by the injection of mycobacterial adjuvant. VIII. Pathologic details of the arthritis and spondylitis. Am J Pathol 1963; 42: 73-95.

' Burstein N A, Waksman B H. The pathogenesis of adjuvant disease in the rat. I. A histologic study of early lesions in the joints and skin. Yale J Biol Med 1964; 37: 177-94.

${ }^{8}$ Mikkelsen W M, Banch T W, Calabro J J, et al. Twenty-fourth rheumatism review. Arthritis Rheum 1981; 24: 113-455.

9 Swingl F, Jaques L W, Kvam D C. Differences in the severity of adjuvant arthritis in four strains of rats. Proc Soc Exp Biol Med 1969; 132: 608-12.

${ }^{10}$ Glenn E M, Gray J. Adjuvant-induced polyarthritis in rats; biologic and histologic background. Am J Vet Res 1965; 26: 1180-94.

${ }^{11}$ Perlik F, Zidek Z. Breeding experiments on the frequency of adjuvant arthritis in the rat. Ann Rheum Dis 1973; 32: 72-4.

12 Muir V Y, Dumonde D C. Quantifying the severity of adjuvant disease of rats objectively. Paper in preparation.

${ }^{13}$ Cromartie W J, Craddock J G, Schwab J H, Anderle S K, Yang $\mathrm{C} \mathrm{H}$. Arthritis in rats after systemic injection of streptococcal cells or cell walls. J Exp Med 1977; 146: 1585-602.

${ }^{14}$ Currey H L F, Ziff M. Suppression of adjuvant disease in the rat by heterologous antilymphocyte globulin. J Exp Med 1968; 127: 185-203.

15 Hehre E, Freund J. Sensitisation, antibody formation and lesions produced by tubercle bacilli in albino rats. Arch Pathol 1939; 27: 289-306.

${ }^{16}$ Oswald N C. Behaviour of tubercle bacilli following their intravenous injection into a resistant animal. Arch Pathol 1940; 29: 678-82.

${ }^{17}$ Alpers J H, Steward M W, Soothill J F. Differences in immune elimination in inbred mice. The role of low antibody affinity. Clin Exp Immunol 1972; 12: 121-32.

${ }^{18}$ Holme G, Piechuta $H$. The derivation of an inbred line of rats which develops asthma-like symptoms following challenge with aerosolised antigen. Immunology 1981; 42: 19-24. 